\title{
Sacroiliac joint fusion health care cost comparison prior to and following surgery: an administrative claims analysis
}

This article was published in the following Dove Press journal:

ClinicoEconomics and Outcomes Research

\author{
Erin K Buysman' \\ Rachel Halpern' \\ David W Polly ${ }^{2,3}$ \\ 'Health Economics and Outcomes \\ Research, Optum, Eden Prairie, MN, \\ USA; '2Department of Orthopedic \\ Surgery, University of Minnesota, \\ Minneapolis, MN, USA; ${ }^{3}$ Department \\ of Neurosurgery, University of \\ Minnesota, Minneapolis, MN, USA
}

Correspondence: Erin K Buysman Health Economics and Outcomes Research, Optum, MNIOI-E300, II 000 Optum Circle, Eden Prairie, MN 55344, USA

Tel +l 9522057758

Fax +l 9522054782

Email erin.buysman@optum.com
Purpose: To assess real-world expenditures on surgical and non-surgical treatment for sacroiliac joint (SIJ) pain by comparing direct health care costs before and after surgery in patients who underwent an SIJ fusion (SIJF) procedure.

Materials and methods: This retrospective observational study examined administrative claims data (January 1, 2010 to February 28, 2017) for adult commercial health plan members with a medical claim for SIJF. Identified patients were included if they had continuous enrollment in the health plan for 12 months pre-SIJF (baseline period) and 12 months post-SIJF (follow-up period). The outcomes of interest were low back pain-related health care costs in the first three quarters of the baseline period (pre-surgery period; excludes the quarter immediately preceding surgery) and last three quarters of the follow-up period (post-surgery period; excludes the quarter in which SIJF was performed).

Results: Some 302 patients met inclusion criteria: 159 patients had the index SIJF in an inpatient hospital setting, 122 in an outpatient hospital setting, 18 in a surgery center, and three in other settings. Mean and median costs in the pre-surgery period were US\$16,803 and US $\$ 5,849$, respectively, and US\$13,297 and US\$2,269 in the post-surgery period. Median costs were significantly different in the pre- and post-surgery periods $(P<0.001)$, while mean costs were not. Median health care costs in the pre-surgery and post-surgery periods were lower than the corresponding means due to the highly skewed nature of the cost data.

Conclusion: This health care claims data analysis shows the potential for lower post-operative health care costs compared to pre-operative costs in patients undergoing SIJF. Median low back pain-related costs in the post-surgery period were approximately US $\$ 400$ per quarter overall and US\$250 per quarter for those undergoing SIJF in the non-inpatient setting. Future studies with larger sample sizes and longer follow-up will improve the precision of the cost data.

Keywords: low back pain, pre-surgery expenditures, post-surgery expenditures

\section{Introduction}

Low back pain is the number one cause of disability worldwide. ${ }^{1}$ Sacroiliac joint (SIJ) pain accounts for between $15 \%$ and $30 \%$ of low back pain..$^{2-6}$ Pain from the SIJ may be even more common in patients with prior lumbar fusion (40\%). ${ }^{7,8}$ Reliable SIJ pain clinical diagnosis can now be made based upon physical examination ${ }^{9}$ with confirmation by image guided injection. SIJ pain reduces quality of life substantially, with impacts as great as other orthopedic conditions such as lumbar spinal stenosis and degenerative hip arthritis. ${ }^{10,11}$

In the past, surgical treatment for this problem was morbid, requiring a major open surgical intervention. ${ }^{12}$ More recently, minimally invasive techniques and associated 
devices for SIJ fusion (SIJF) have become available; these have lessened the morbidity of surgery and improved clinical outcomes. The most commonly studied devices, triangular titanium implants, have been the subject of two prospective randomized controlled trials, ${ }^{13,14}$ a large prospective multicenter trial ${ }^{15}$ and several retrospective case series. ${ }^{16-18}$ While non-surgical treatments for SIJ pain are commonly provided, high-quality evidence to support the long-term effectiveness of physical therapy, intraarticular steroid injections, radiofrequency ablation and other treatments is lacking.

In most settings, modern health care needs outweigh resources. A rational approach to resource allocation is to use cost-effectiveness measures to decide which services and products should be covered. As new interventions become available, it is important to develop data to evaluate their costeffectiveness. Costs of care include direct medical costs (the actual costs of care) as well as indirect costs, such as loss of worker productivity, retraining costs, caregiver burden, etc.

One approach to examining cost-effectiveness is the budget-impact model. This approach looks at overall costs to society from providing a given treatment. Some treatments, such as surgery, have high upfront costs. In contrast, non-operative care typically has lower initial costs but the possibility of ongoing or recurrent costs if such treatments have only modest effectiveness. If surgery effects are durable, then at some point in time, there will be a crossover point when surgery and post-surgical health care services over time are less expensive than ongoing non-surgical care. Finding real-world data for this crossover point can be challenging.

The goal of the current analysis was to assess the realworld expenditures on surgical treatment for SIJ pain using an administrative claims database by comparing direct health care costs prior to and following surgery in patients who underwent an SIJF procedure.

\section{Materials and methods \\ Study design and data sources}

This retrospective observational study was conducted using administrative claims data from a large US health insurer affiliated with Optum, Inc. between January 1, 2010 and February 28, 2017. This was a retrospective analysis of statistically certified de-identified data; data were extracted with processes compliant with the Health Insurance Portability and Accountability Act of 1996, and therefore did not require institutional review board approval.

The administrative claims database included demographic information as well as medical claims data from physicians and facilities and outpatient pharmacy claims data. The patients represented in the database were geographically diverse, with most enrollees in the South and Midwest US Census regions, and approximately 14.6 million commercially insured adult enrollees in 2016. "Administrative claims" refers to computerized records generated when a US patient has a healthcare interaction that is submitted by a health care practitioner to a health insurer for payment. Claims include ICD, Ninth Revision, Clinical Modification (ICD-9-CM) and ICD-10-CM diagnosis and procedure codes, Current Procedural Terminology $\left(\mathrm{CPT}^{\circledR}\right)$ procedure codes, Healthcare Common Procedure Coding System (HCPCS) codes, site of service codes, and health plan and patient paid costs. Outpatient pharmacy data include National Drug Codes (NDC) for dispensed medications, as well as cost information.

\section{Patient selection}

Adult commercial health plan members with a medical claim with a CPT code for SIJF fusion (CPT codes 27279 , $27280,0334 \mathrm{~T}$ ) during the identification period January 1 , 2011 through February 29, 2016 were identified. The index date was defined as the date of the SIJF procedure during the identification period. Commercially insured patients were included if they were between 18 and 64 years old as of the index year and had continuous enrollment in the health plan with medical and pharmacy benefits for 12 months (360 days) prior to the index date (baseline period) and for 12 months beginning on the index date (follow-up period). "Enrollment" refers to the period of time in which a particular patient was covered under a particular health insurance program during which claims submitted and approved for payment would be covered by the insurance company. Patients with evidence of long fusion to the sacrum, a procedure typically performed for adult scoliosis, defined as having a claim with a procedure code for lumbar arthrodesis within 7 days before or after the index date (CPT codes observed in the study sample: 22558 , 22612, 22630, 22633, 63102), were excluded from the final analytic sample due to the more complex nature of patients undergoing this procedure. The SIJF procedure setting was categorized as occurring in an inpatient hospital setting, an outpatient hospital setting, a surgical center, or at some other site based on the site of service on the SIJF claim.

\section{Study measures}

The outcomes of interest were low back pain-related costs in the baseline and follow-up periods. We measured low back pain-related costs because SIJ pain may be mistaken for low back pain and because there are not diagnosis codes specific to only SIJ pain. Pain cannot be observed directly in the 
claims data; we therefore assumed that health care resource utilization and costs were associated with low back pain based on diagnosis and procedure codes associated with the claims. To identify claims related to SIJ pain, all ICD-9-CM and ICD10-CM diagnosis and procedure codes, CPT codes, HCPCS codes, and NDC codes for outpatient pharmacy prescriptions during the baseline and follow-up periods for patients in the final sample were reviewed by a physician who determined whether the code would likely be used for services related to low back pain. Codes from both the baseline and followup periods were assessed together, so that the timing of the occurrence of the code would not influence the physician reviewer's decision as to whether or not a particular code was considered SIJ pain-related. Medical costs included both physician and facility claims that had diagnosis or procedure codes for low back pain and/or its treatment and were the sum of patient-paid and health plan-paid amounts. Outpatient pharmacy costs were the sum of patient-paid and health plan-paid costs for pain-related medication fills that occurred within 7 days following a medical claim related to low back pain. All costs were adjusted to 2016 US dollars using the medical care component of the Consumer Price Index from the US Bureau of Labor Statistics. ${ }^{19}$

The baseline and follow-up periods were each divided into four 90-day quarters (Figure 1). Costs in the first three quarters of the baseline period (quarters 1-3) were assumed to be associated with treating low back pain medically (without surgery). Costs in the last quarter of baseline (quarter 4) were excluded as low back pain management expenditures due to their proximity to the index procedure; we assumed that patients were likely to have different utilization patterns once they decided to proceed with, and prepare for, surgery. Costs in the first quarter of the follow-up (quarter 5) were not counted as post-surgery expenditures because they included the costs of the SIJF surgery. Costs in the last three quarters of the follow-up period (quarters 6-8) were assumed to be those associated with low back pain in the post-surgery period.

Demographic characteristics were age, sex, US Census region of the patient. Baseline comorbidities were defined using the Clinical Classification Software managed by the Agency of Healthcare Research and Quality, ${ }^{20}$ which aggregates diagnosis codes into specific disease conditions, and were identified with binary indicator variables. The QuanCharlson comorbidity score ${ }^{21}$ was also calculated in the baseline period as a general measure of severity in the study sample. An indicator variable identifying any opioid use in the baseline period was created.

\section{Statistical analysis}

All demographics, baseline characteristics and outcome measures were analyzed descriptively. Comparisons between mean pre-surgery costs (quarters 1-3) and post-surgery costs (quarters 6-8) were made using paired $t$-tests; because of the highly skewed nature of costs, median costs and Wilcoxon signed rank tests were also evaluated. Analyses were conducted using SAS 9.4 (SAS Institute, Cary, NC, USA).

\section{Results}

The selection criteria yielded a sample of 339 patients; 37 patients were excluded due to claims with procedure codes for long fusion to the sacrum, resulting in a final sample of 302 patients. Of these, 159 patients had the index SIJF in an inpatient hospital setting, 122 in an outpatient hospital setting, 18 in a surgery center, and three in other settings.

The demographic and baseline characteristics of the final patient sample are provided in Table 1. Most patients were aged 45-64, and the sample was predominantly female. The mean (SD) Quan-Charlson comorbidity score was 0.6 (1.2); nearly two-thirds of patients had a score of zero, indicating a relatively healthy population. The most common

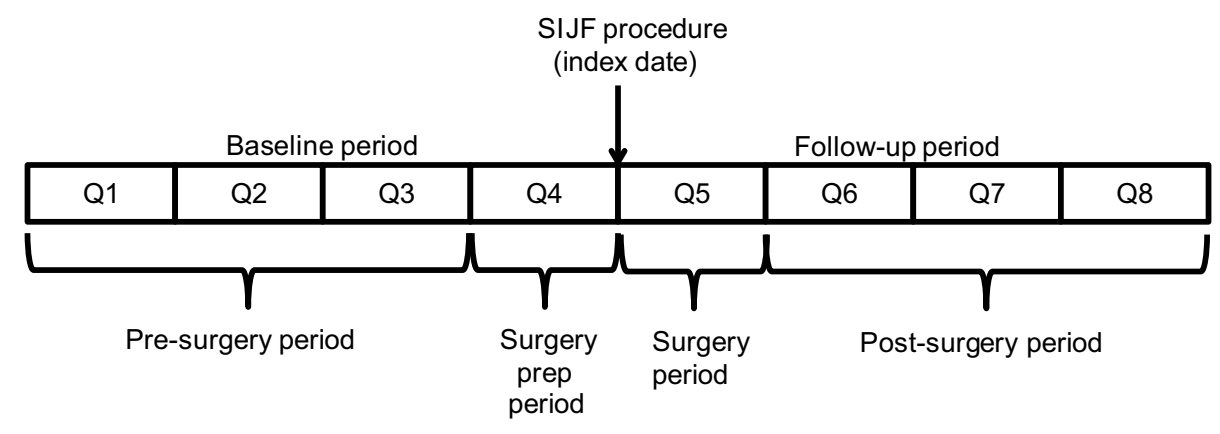

Figure I Study periods.

Abbreviations: SIJF, sacroiliac joint fusion; Q, quarter. 
Table I Patient demographics and characteristics

\begin{tabular}{ll}
\hline Variable & Value \\
\hline Age (years), mean (SD) & $49.1(8.9)$ \\
$\geq 45$ years, $\mathrm{n}(\%)$ & $214(70.9)$ \\
Female gender, $\mathrm{n}(\%)$ & $218(72.2)$ \\
US census region, $\mathrm{n}(\%)$ & \\
Northeast & $16(5.3)$ \\
Midwest & $1 \mathrm{II}(36.8)$ \\
South & $135(44.7)$ \\
West & $40(13.2)$ \\
Quan-Charlson comorbidity index, mean (SD) & $0.6(1.2)$ \\
Categorical Quan-Charlson comorbidity index, $\mathrm{n}(\%)$ & \\
0 & $194(64.2)$ \\
I-2 & $90(29.8)$ \\
$3-4$ & $9(3.0)$ \\
$\geq 5$ & $9(3.0)$ \\
Comorbidities, $\mathrm{n}$ (\%) & \\
Other nervous system disorders & $179(59.3)$ \\
Hypertension & $123(40.7)$ \\
Respiratory infections & $120(39.7)$ \\
Diseases of the urinary system & $118(39.1)$ \\
Disorders of lipid metabolism & $116(38.4)$ \\
Diseases of the heart & $104(34.4)$ \\
Other nutritional, endocrine, and metabolic disorders & $102(33.8)$ \\
Baseline opioid use, $\mathrm{n}$ (\%) & $269(89.1)$ \\
\hline
\end{tabular}

comorbidities in the population included other nervous system disorders $(59.3 \%)$, hypertension $(40.7 \%)$, respiratory infections (39.7\%), diseases of the urinary system (39.1\%), disorders of lipid metabolism (38.4\%), diseases of the heart $(34.4 \%)$, and other nutritional, endocrine, and metabolic disorders $(33.8 \%)$.

Mean and median low back pain-related costs in each of the four quarters prior to and following SIJF are presented in Figure 2; costs in quarter 5 (the first quarter of the follow-up period) include those for the index SIFJ. Mean and median low back pain-related costs in the pre-surgery period (first three quarters of the baseline period) and in the post-surgery period (last three quarters of the follow-up period) are provided in Figure 3, both in the overall sample and stratified by the setting of the index SIJF procedure. Patients with SIJF in the "other" setting are not presented in the stratification due to small sample sizes. Median costs were statistically significantly different between the pre- and post-surgery periods among patients whose index SIJF was performed in inpatient and outpatient hospital settings.

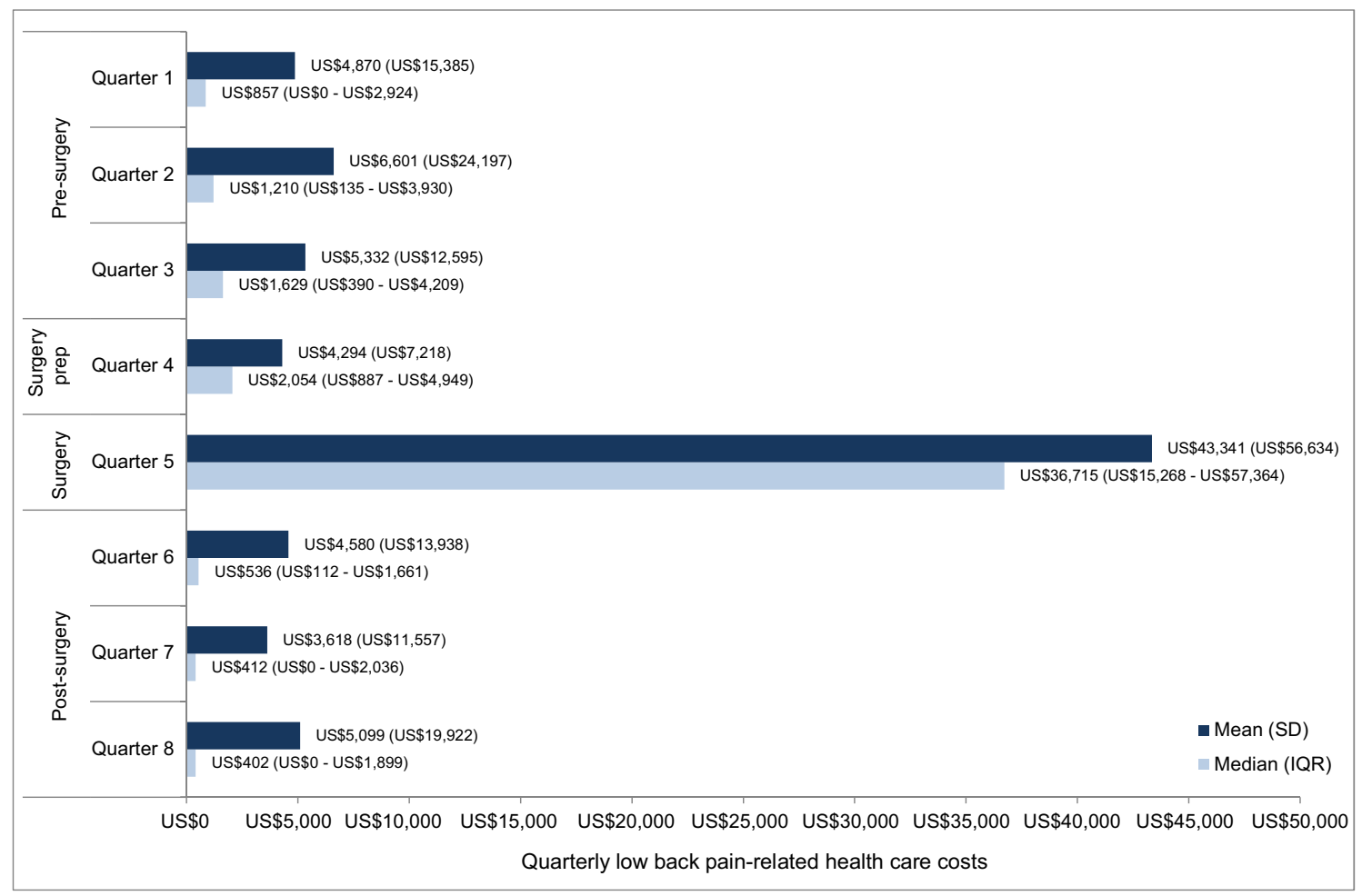

Figure 2 Quarterly low back pain-related costs.

Note: All costs are presented in US\$. 


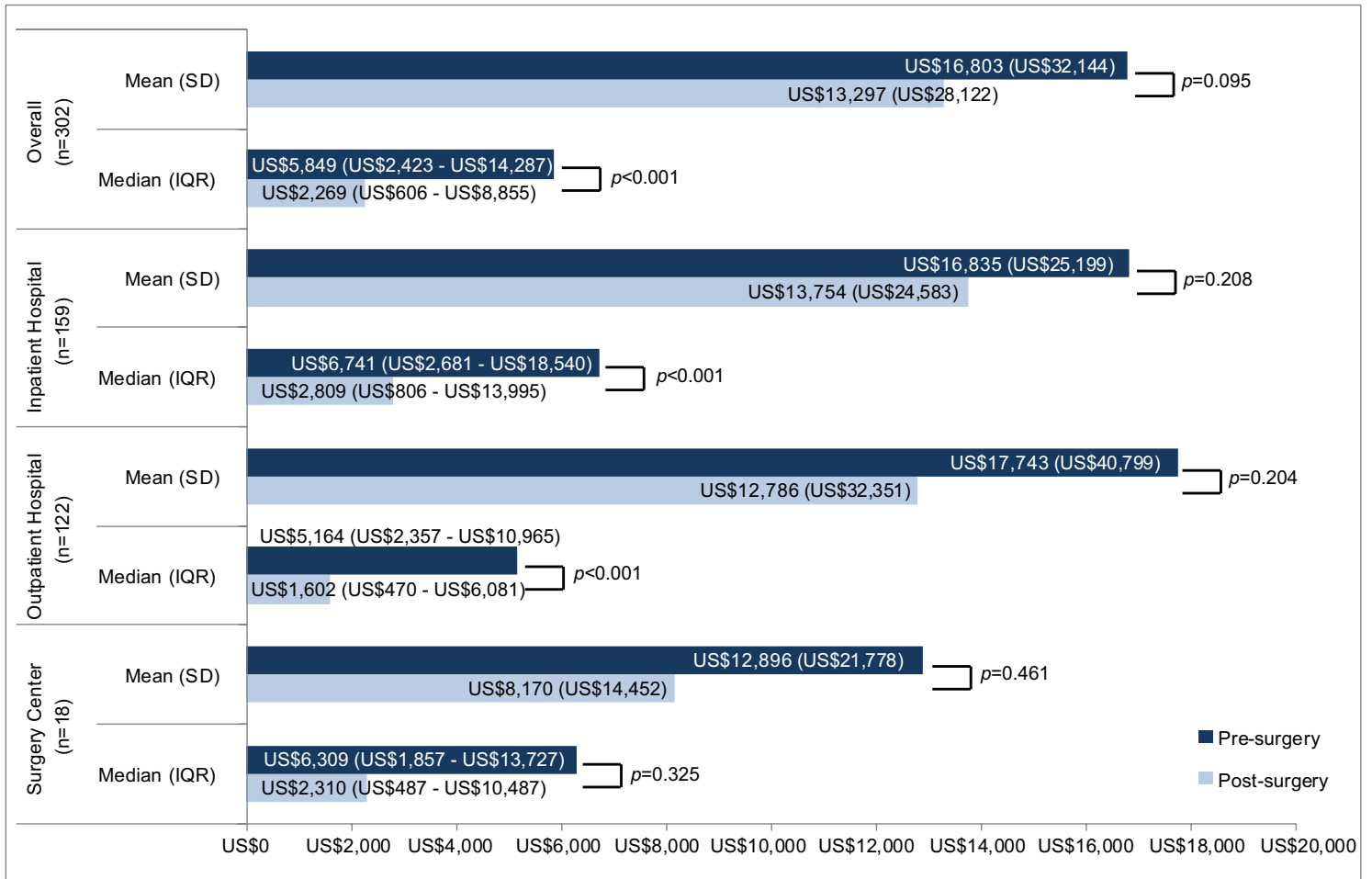

Figure 3 Pre-surgery vs post-surgery low back pain-related costs.

Notes: $P$-values comparing pre-surgery to post-surgery mean/median costs. All costs are presented in US\$.

\section{Discussion}

In this analysis, the mean pre-surgery (4-12 months prior to SIJF) and post-surgery (4-12 months following SIJF) low back pain-related health care costs were US $\$ 16,803$ and US $\$ 13,297$, respectively, with similar relationships between pre-surgery and post-surgery costs in the subsets of patients with SIJF in inpatient and outpatient settings. Non-parametric tests accounting for the skewed nature of cost data showed statistically significant lower median costs post-surgery compared with pre-surgery overall and in the inpatient and outpatient venues. Median health care costs in the pre-surgery and post-surgery periods were lower than the corresponding means due to a small number of high cost patients. Examination of detailed medical claims data from high cost patients showed that some had received additional surgical interventions for low back pain (primarily lumbar fusion). Mean and median surgical and post-surgical costs appeared to be lower among patients who underwent their SIJF procedure in an outpatient setting compared to patients having surgery in an inpatient setting, although we did not compare those costs with statistical tests.

In light of prospective randomized controlled trials showing marked immediate and sustained improvement in pain, disability and quality of life after SIJF compared to non-surgical treatment ${ }^{13,14}$ along with relatively low surgical revision rates, ${ }^{22}$ our health care cost findings suggest that SIJF may constitute a reasonable economic strategy as well. To put the health care costs reported above into perspective, we used data from Figure 3 in a simple cumulative cost model, the aim of which was to calculate and compare cumulative low back pain-related health care costs after SIJF or after continued non-surgical treatment. We estimated the cost of the SIJF procedure, which occurred at the beginning of quarter 5 , by subtracting the average quarterly pre-surgery (quarters 1-3) low back pain-related health care costs from total low back pain-related costs during quarter 5 . We estimated ongoing post-operative low back pain-related health care costs after SIJF as the average quarterly post-surgery costs (quarters 6-8), assuming that these costs would continue at a consistent level over time. For non-surgical treatment, our counterfactual, we assumed that ongoing non-surgical health care costs were estimated by costs incurred in the pre-surgery period because nonsurgical treatment has not been shown to produce long-term improvements in pain or disability related to SIJ pain; we further assumed these costs would continue at a consistent level over time after the 12-month period observed in our study. In estimating non-surgical costs, we removed the 
quarter immediately prior to surgery as patients would likely undergo preoperative testing potentially unrelated to back pain itself. These assumptions yielded a model showing that cumulative low back pain-related health care costs associated with SIJF and non-surgical treatment "crossed" (ie, reached "break-even"; see Figure 4) at 7.25 years. In the subgroups of patients undergoing SIJF in the inpatient and outpatient settings, break-even costs occurred at 11.75 and 2.5 years, respectively. No study of surgical interventions for low back pain that the authors know of has shown lower cumulative costs vs non-surgical treatment.

We interpret the above extension of our results cautiously, particularly the extrapolation of constant costs beyond the end of our 12-month study period. A direct comparison of health care costs between surgical and non-surgical treatment strategies may be accomplished through randomized clinical trials, though whether such results apply to the real-world setting is unclear. A "realworld" observational case-control study of surgical vs non-surgical intervention would be limited because of the ability to select a control population that is comparable to cases receiving SIJF given the possible misdiagnosis of SIJ pain. Perhaps more importantly, a comparison of patients with SIJ pain who choose to undergo surgical treatment vs those who receive ongoing non-surgical treatment would likely be confounded by increased severity of illness in patients who undergo surgery (ie, patients with higher degrees of SIJ pain may choose more invasive, and consequently expensive, treatments). As an alternative, we used an epidemiologic design ${ }^{23}$ in which the counterfactual, ie, health care costs in a surgical cohort had surgery not been performed, was estimated by pre-surgery costs. Advantages of this design include the ability to control for inter-patient differences since each patient serves as his/ her own control. These real-world costs could be applied as the foundation of a budget-impact model that could also account for the venue of SIJF. Nevertheless, our assumptions about consistent health care expenditures over time, particularly given 12 months of pre-index and post-index data, are substantial.

Cost-effectiveness studies in spine surgery have been increasing in recent years. ${ }^{24}$ Much of this work has been dependent upon cost estimates rather than actual costs. Some institutions have been able to identify actual costs. ${ }^{25-28}$ One of the most difficult set of costs to capture, especially outside of clinical trials, has been the non-operative costs of care. In some trials patient diaries of non-operative resource utilization have been used and then Medicare reimbursement amounts costs applied. In very few studies have the actual costs been captured. With the advent of large payer-based databases, there is now the possibility to accurately capture cost data. The accurate determination of non-operative cost data will better inform future cost-effectiveness studies going forward. It will also allow modeling of break-even points when surgery is costly but obviates some degree of recurring non-operative care.

\section{Limitations}

Some limitations inherent to claims data should be considered when interpreting the results from this study. The administrative claims data used in this study were collected for the purpose of payment rather than research and their usefulness depend on the accuracy of the data in the database. Claims data may be subject to coding errors, and the presence of a diagnosis code on a medical claim may not always indicate disease (eg, it may be included as rule-out criteria). Because SIJ pain may often be misidentified as low back pain, we categorized all health care interventions according to whether the intervention was aimed more generally at low back pain. Because of this potential for misidentification, it is likely that we included treatments that targeted other causes of low back pain, which are not treated with SIJF, which may result in overestimated costs attributed to the SIJ and increasing the variation in costs. Whether excluding potential non-SIJ-related resource consumption would have impacted pre- vs post-operative SIJF costs is not known. Clinical characteristics such as pain scores and radiology findings were not available in the claims data and could not be utilized to refine the study population. In addition, clinical information indicating the success of the SIJF procedure was not known and could not be used to determine if post-surgery low back pain-related services were due to a partially successful or unsuccessful SIJF, to new low back problems, or typical post-surgery follow-up. Additional patient characteristics that may have provided insights into patient outcomes such as race/ethnicity and socioeconomic status were not available in the data. Also, the analyses in this study were performed using commercially insured patients enrolled in a managed care plan, and the results may not be generalizable to other patient populations. Finally, our analysis focused on direct health care costs only. Because SIJ pain affects the working-age population, the economic impact of low back pain surgical interventions on indirect costs (eg, disability payments, retraining, loss of productivity) is both of interest and remains to be investigated. 
A

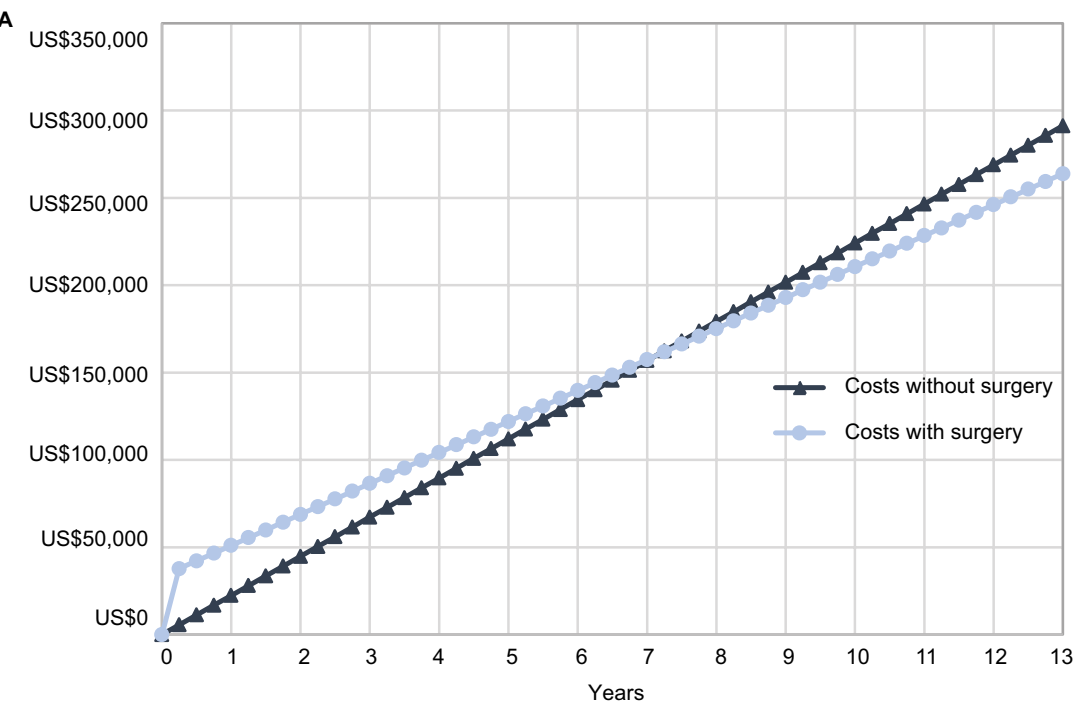

B

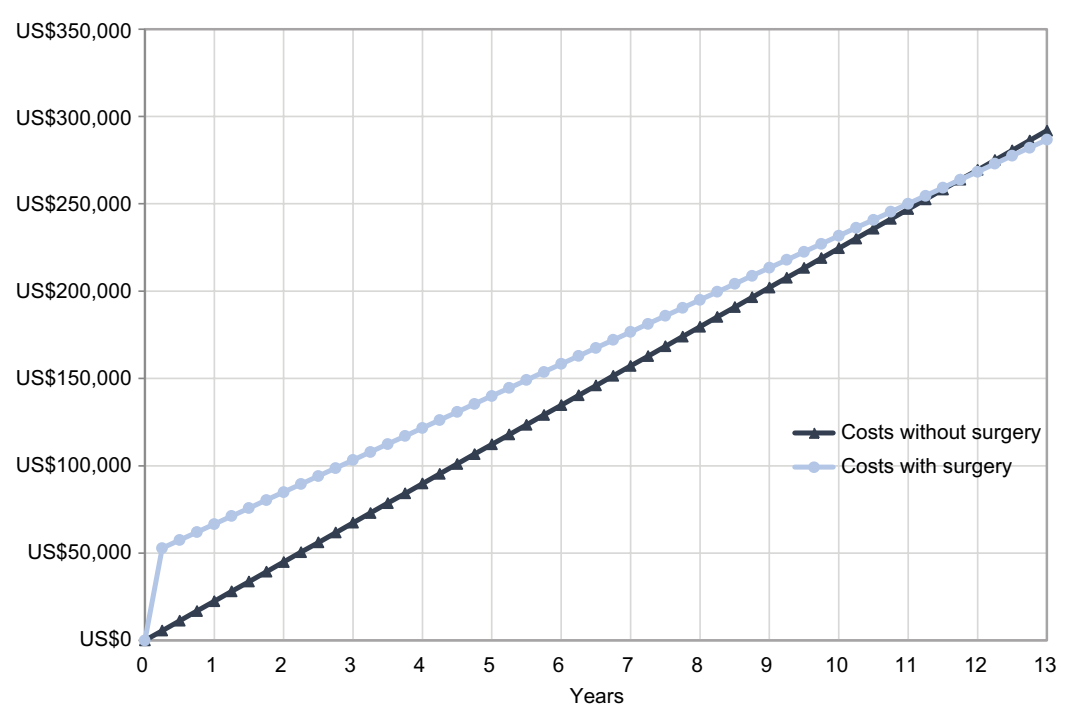

C

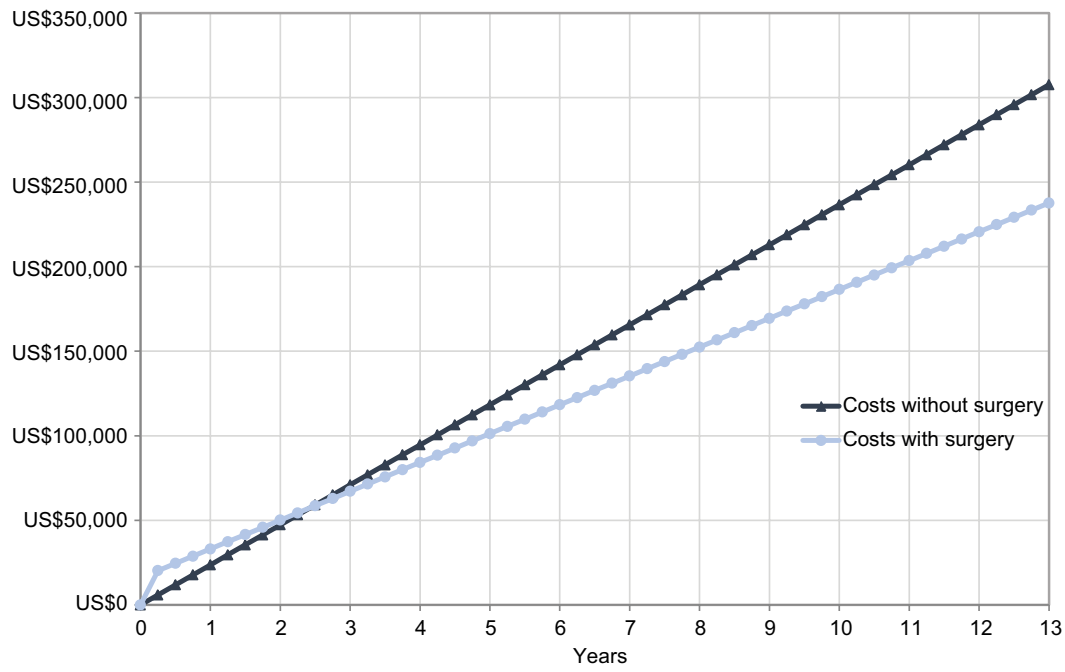

Figure 4 Break-even analysis of surgical vs non-surgical treatment (A) overall, (B) in the inpatient setting, and (C) in the outpatient setting. Note: All costs are presented in US\$. 


\section{Conclusion}

This analysis of commercial health care claims data shows the potential for lower post-operative low back pain-related health care costs compared to pre-operative costs. Median low back pain-related costs in the post-surgery time period were approximately US $\$ 400$ per quarter overall and US $\$ 250$ per quarter for those undergoing SIJF in the non-inpatient setting. Additional studies with larger sample size and longer length of follow-up are warranted to improve the precision of the cost data.

\section{Acknowledgments}

Funding for this study was provided by SI-BONE, Inc. Daniel Cher, MD, of SI-BONE, Inc. provided clinical expertise and conceptualization of the cross-over design for this study. Jerald Seare, MD, of Optum provided clinical coding expertise. Caitlin Elliott, MS, and Randall Gerdes of Optum provided data programming and analytic support. Virginia Rosen, $\mathrm{PhD}$, of Optum provided editorial support in preparing the manuscript for submission.

\section{Author contributions}

E.B. co-developed the analysis plan, participated in dataset construction and statistical analysis and interpreted the study results, participated in drafting the manuscript, and approved the final version for submission; and is willing to be accountable for the accuracy and integrity of the work. R.H. co-developed the analysis plan, interpreted the study results, participated in drafting the manuscript, and approved the final version for submission; and is willing to be accountable for the accuracy and integrity of the work. D.P. interpreted the study results, revised the manuscript critically for important intellectual content, and approved the final version for submission; and is willing to be accountable for the accuracy and integrity of the work.

\section{Disclosure}

E.B and R.H. are employees of Optum, under contract with SI-BONE, Inc. D.P is an employee of the University of Minnesota and University of Minnesota Physicians and has no industry conflicts of interest.

\section{References}

1. Hoy DG, Smith E, Cross M, et al. The global burden of musculoskeletal conditions for 2010: an overview of methods. Ann Rheum Dis. 2014;73(6):982-989.

2. Sembrano JN, Polly DW. How often is low back pain not coming from the back? Spine. 2009;34(1):E27-E32.

3. Bernard TN, Kirkaldy-Willis WH. Recognizing specific characteristics of nonspecific low back pain. Clin Orthop Relat Res. 1987;(217):266-280.
4. Schwarzer AC, Aprill CN, Bogduk N. The sacroiliac joint in chronic low back pain. Spine. 1995;20(1):31-37.

5. Maigne JY, Aivaliklis A, Pfefer F. Results of sacroiliac joint double block and value of sacroiliac pain provocation tests in 54 patients with low back pain. Spine. 1996;21(16):1889-1892.

6. Irwin RW, Watson T, Minick RP, Ambrosius WT. Age, body mass index, and gender differences in sacroiliac joint pathology. Am J Phys Med Rehabil. 2007;86(1):37-44.

7. Liliang PC, Lu K, Liang CL, Tsai YD, Wang KW, Chen HJ. Sacroiliac joint pain after lumbar and lumbosacral fusion: findings using dual sacroiliac joint blocks. Pain Med. 2011;12(4):565-570.

8. Depalma MJ, Ketchum JM, Saullo TR. Etiology of chronic low back pain in patients having undergone lumbar fusion. Pain Med. 2011;12(5):732-739.

9. Petersen T, Laslett M, Juhl C. Clinical classification in low back pain: best-evidence diagnostic rules based on systematic reviews. $B M C$ Musculoskelet Disord. 2017;18(1):188.

10. Cher D, Polly D, Berven S. Sacroiliac joint pain: burden of disease. Med Devices. 2014;7:73-81.

11. Cher DJ, Reckling WC. Quality of life in preoperative patients with sacroiliac joint dysfunction is at least as depressed as in other lumbar spinal conditions. Med Devices. 2015;8:395-403.

12. Stark JG, Fuentes JA, Fuentes TI, Idemmili C. The history of sacroiliac joint arthrodesis: A critical review and introduction of a new technique. Curr Orthop Prac. 2011;22(6):545-557.

13. Polly DW, Swofford J, Whang PG, et al; the INSITE Study Group. twoyear outcomes from a randomized controlled trial of minimally invasive sacroiliac joint fusion vs. non-surgical management for sacroiliac joint dysfunction. Int J Spine Surg. 2016;10:28.

14. Dengler JD, Kools D, Pflugmacher R, et al. 1-year results of a randomized controlled trial of conservative management vs. minimally invasive surgical treatment for sacroiliac joint pain. Pain Physician. 2017;20(6):537-550.

15. Duhon BS, Bitan F, Lockstadt H, Kovalsky D, Cher D, Hillen T; SIFI Study Group. Triangular titanium implants for minimally invasive sacroiliac joint fusion: 2-year follow-up from a prospective multicenter trial. Int J Spine Surg. 2016;10:13.

16. Vanaclocha V, Herrera JM, Sáiz-Sapena N, Rivera-Paz M, VerdúLópez F. Minimally invasive sacroiliac joint fusion, radiofrequency denervation, and conservative management for sacroiliac joint pain: 6-year comparative case series. Neurosurgery. 2018;82(1): $48-55$.

17. Rudolf L, Capobianco R. Five-year clinical and radiographic outcomes after minimally invasive sacroiliac joint fusion using triangular implants. Open Orthop J. 2014;8:375-383.

18. Sachs D, Kovalsky D, Redmond A, et al. Durable intermediate-to long-term outcomes after minimally invasive transiliac sacroiliac joint fusion using triangular titanium implants. Med Devices. 2016;9: 213-222.

19. U.S. Bureau of Labor Statistics. Measuring Price Change for Medical Care in the CPI; 2010. Available from: http://www.bls.gov/cpi/cpifact4. htm\#1a. Accessed January 3, 2017.

20. Clinical Classifications Software (CCS) for ICD-9-CM; 2018. Available from: https://www.hcup-us.ahrq.gov/toolssoftware/ccs/ccs.jsp. Accessed January 3, 2018.

21. Quan H, Sundararajan V, Halfon P, et al. Coding algorithms for defining comorbidities in ICD-9-CM and ICD-10 administrative data. Med Care. 2005;43(11):1130-1139.

22. Cher DJ, Reckling WC, Capobianco RA. Implant survivorship analysis after minimally invasive sacroiliac joint fusion using the iFuse Implant System $^{\circledR}$. Med Devices. 2015;8:485-492.

23. Redelmeier DA. The exposure-crossover design is a new method for studying sustained changes in recurrent events. $J$ Clin Epidemiol. 2013;66(9):955-963.

24. Alvin MD, Miller JA, Lubelski D, et al. Variations in cost calculations in spine surgery cost-effectiveness research. Neurosurg Focus. 2014;36(6):E1. 
25. Glassman SD, Polly DW, Dimar JR, Carreon LY. The cost effectiveness of single-level instrumented posterolateral lumbar fusion at 5 years after surgery. Spine. 2012;37(9):769-774.

26. Glassman SD, Carreon LY, Shaffrey CI, et al. The costs and benefits of nonoperative management for adult scoliosis. Spine. 2010;35(5): $578-582$.
27. Gum JL, Hostin R, Robinson C, et al. Impact of cost valuation on costeffectiveness in adult spine deformity surgery. Spine J. 2017;17(1): 96-101.

28. Gum JL, Carreon LY, Kelly MP, et al. Cell saver for adult spinal deformity surgery reduces cost. Spine Deform. 2017;5(4):272-276.
ClinicoEconomics and Outcomes Research is an international, peerreviewed open-access journal focusing on health technology assessment, pharmacoeconomics and outcomes research in the areas of diagnosis, medical devices, and clinical, surgical and pharmacological intervention. The economic impact of health policy and health systems

\section{Dovepress}

organization also constitute important areas of coverage. The manuscript management system is completely online and includes a very quick and fair peer-review system, which is all easy to use. Visit http://www.dovepress.com/testimonials.php to read real quotes from published authors.

Submit your manuscript here: https://www.dovepress.com/clinicoeconomics-and-outcomes-research-journal 